\section{Time for a definition of citizen science}

As founders of the Austrian Citizen Science Network

(www.citizen-science.at), we call for the standardization of citizen science. This would optimize quality and ensure openness in the science, in communication and in cooperation, and enable compliance with legislation such as that on data privacy.

Citizen science, in which amateurs participate in research, is gaining momentum in the scientific literature, but it is still not clearly defined. Various approaches and concepts are in use in different countries, for example (M. V. Eitzel et al. Citiz. Sci. Theory Pract. 2, 1; 2017). If citizen science is to be fostered by funding agencies (as planned) and applied more often by scientists, we need a rigorous definition of method to safeguard the reputation of research and the value of public participation.

Individual projects have taken steps to this end, but a broader vision and greater coordination are needed. Our working group is developing an open framework and a catalogue of quality criteria for evaluating citizen-science projects with a view to inspiring other platforms, networks and scientists to do the same (see B. Kieslinger et al. Preprint at SocArXiv http://doi.org/cfr8; 2017). Citizen science must not become what its critics claim it to be: poor science with great communication potential.

Florian Heigl, Daniel Dörler University of Natural Resources and Life Sciences Vienna, Austria. florian.heigl@boku.ac.at

\section{Research videos in indigenous languages}

The winning videos of the first multilingual competition for science popularization, ImaginePanGea, are now available with subtitles in ten languages, including Tsonga (also known as Changana), the native language of Mozambique, and Guaraní, a language used by indigenous people in parts of South America (http://projetoimagine.ufsc.br/en).

The competition was organized by the Imagine Project in partnership with the Brazilian Society for the Advancement of Science and two sciencepopularization networks RedPOP in Latin America and the Caribbean, and African Gong in Africa. The aim was to democratize knowledge and stimulate a taste for science in people who usually have little or no access to it. The 55 competitors were graduate students at institutions in those regions. They submitted three-minute videos on their research topics, presented so that people anywhere could understand them.

Translation was tricky, particularly for languages that are not traditionally influenced by academic vocabulary. As pointed out by translator Joana Mongelo - the first Guaraní science master's graduate in southern Brazil — various terms in the videos do not exist in her native language and so had to remain in Portuguese. Further translations are planned, including into Yoruba (a language from West Africa) and the Bantu languages Umbundu and Kimbundu, spoken in Angola.

André Ramos Federal University of Santa Catarina, Florianópolis, Brazil.

andre.ramos@ufsc.br

\section{Developing standard measures for biology}

The UK National Measurement Laboratory is working as part of a global effort to standardize measurements on biological materials. The aim is to ensure that disease diagnosis and management is based on reproducible research results (see also M. Sené et al. Nature 547, 397-399; 2017).

Aside from the enormity of the task for fields ranging from genetic sequencing to cell-based therapies, we must define and develop systems for measuring biological components that can be unstable, heterogeneous or present at ultra-low concentrations in complex environments.

Furthermore, conventional approaches to measurement may no longer be applicable. We therefore need to redefine which units are useful and how uncertainty should be determined for biological molecules. It is also crucial to keep pace with rapid technological advances.

Institutes such as ours are leading the consultation with the research, clinical and health-care communities to set standards for best laboratory practice and supporting materials, and to provide training in scientific methods and data analysis to ensure that research results are reproducible.

Julian Braybrook UK National Measurement Laboratory, LGC Group, Teddington, UK. julian.braybrook@lgcgroup.com Competing financial interests declared: go.nature.com/2xpuoy7.

\section{Track social impact of grant types in Africa}

African grant-giving bodies need more evidence on the economic and social impact of different types of research funding with respect to the scale, duration and orientation of grants. The issue will be discussed at this month's annual forum of the Science Granting Councils Initiative in Livingstone, Zambia.

This lack of data on the broader outcomes of funding mechanisms became evident during a study we conducted this year, sponsored by Canada's International Development Research Centre, the UK Department for International Development and South Africa's National Research Foundation. We investigated the political and economic factors that influence the African science-granting councils (see go.nature.com/2zwohjm).

African researchers are under particular pressure to contribute to their countries' economic or social development. This means that evidence of scholarly impact, such as publication numbers, is of limited use to African funding bodies because such metrics rarely extend beyond evaluation of individual researchers and bear limited relevance to social and economic impact.

Joanna Chataway University of Sussex, Brighton, UK.

Rebecca Hanlin African Centre for Technology Studies, Nairobi, Kenya.

r.hanlin@acts-net.org

\section{Seven LIGO authors not accounted for}

Your report on the Laser Interferometer GravitationalWave Observatory (LIGO) collaboration that led to the discovery of the first gravitational waves in 2015 (Nature http://doi. org/cfsp; 2017) refers to "a mindboggling 1,004 authors" on the resulting paper (B. P. Abbott et al. Phys. Rev. Lett. 116, 061102; 2016). In fact, a little copy-andpasting and a few minutes fiddling around in a spreadsheet indicates that there are 1,011 authors.

Such a discrepancy (a counting error rate of $0.7 \%$ ) might not seem to matter too much in the cosmic scheme of things - after all, it's not that big a deal compared with black holes colliding. But it does matter: bibliometrics depends on accurate data.

Self-correction is crucial for sound science. There is no shame in a small slip up, provided the record is promptly corrected. And sensational claims, even those with apparently minor implications, still need to be factchecked - particularly if they are being perpetrated in the media, as in this case.

Michael Twidale University of Illinois at Urbana-Champaign, USA.

twidale@illinois.edu 